\title{
POR UMA CARACTERIZAÇÃO DOS CONSTITUINTES TEXTUAIS DESGARRADOS COMO COMENTÁRIOS PARENTÉTICOS À LUZ DE UMA PERSPECTIVA MODULAR DA ORGANIZAÇÃO DO DISCURSO
}

\author{
Gustavo Ximenes CUNHA* \\ Maria Beatriz Nascimento DECAT ${ }^{* *}$
}

- RESUMO: Neste trabalho, nosso intuito é evidenciar que o desgarramento de constituintes, visto por Decat (2011) como estruturas que ocorrem livremente, sem estarem vinculadas sintaticamente a nenhuma oração ou nenhuma outra porção textual, pode ser estudado à luz de uma abordagem da Linguística do Texto e do Discurso, o Modelo de Análise Modular do Discurso. Mais especificamente, estendemos ao estudo dos constituintes desgarrados a proposta de Roulet (2004) para o tratamento dos constituintes parentéticos. Neste trabalho, seguiremos um percurso de análise que estudará o fenômeno do desgarramento em três etapas. Na primeira, estudaremos a relação textual que liga um constituinte desgarrado a uma informação previamente abordada no texto. Na segunda etapa, analisaremos a relação praxiológica que articula a ação que se realiza com o constituinte desgarrado às ações previamente realizadas. Por fim, a terceira etapa estuda os constituintes desgarrados do ponto de vista da forma de organização operacional. Nessa última etapa, os resultados das etapas anteriores serão combinados com o fim de compreendermos as motivações discursivas para o emprego dos constituintes desgarrados. Nas diferentes etapas, os constituintes desgarrados que analisaremos foram extraídos de textos da mídia, como reportagens e artigos de opinião.

- PALAVRAS-CHAVE: Constituintes desgarrados. Constituintes parentéticos. Modularidade.

\section{Introdução}

Mais do que um fenômeno estritamente sintático, o desgarramento de constituintes textuais é um recurso de formulação textual motivado por razões pragmáticas. Como evidenciado por Decat (2011), são considerados desgarrados ou soltos constituintes textuais, como sintagmas nominais ( $\mathrm{SNs}$ ), orações relativas apositivas (adjetivas

\footnotetext{
Universidade Federal de Minas Gerais (UFMG). Belo Horizonte - MG - Brasil. ximenescunha@yahoo.com.br ORCID: 0000-0001-9953-1204.

** Universidade Federal de Minas Gerais (UFMG). Belo Horizonte - MG - Brasil. bdecat@uol.com.br. ORCID: 00000003-2464-2617.
} 
explicativas) ou orações adverbiais, que "ocorrem livremente, sem estarem vinculados sintaticamente a nenhuma oração" (DECAT, 2011, p. 74). No excerto (0), extraído de um artigo de opinião, o trecho sublinhado constitui um exemplo de uma relativa apositiva desgarrada.

0. A democracia representativa falhou em garantir o respeito aos anseios de sociedades plurais e complexas. Isso não significa, por outro lado, que a solução seja negar a política e suas instituições. Que podem não ser perfeitas, mas é o que temos neste momento. (SAKAMOTO, 2018, grifo nosso).

Quanto à função desses constituintes desgarrados, esclarece Decat (2011, p. 81-82):

A necessidade de reforçar um ponto de vista, de dar realce, ênfase a um determinado aspecto, leva o produtor do texto a fazer uso de sequências argumentativas, materializadas linguisticamente através da estratégia do 'desgarramento' de orações ou de SNs.

Nesse sentido, o desgarramento de constituintes textuais é um fenômeno complexo, já que seu estudo implica não apenas informações de natureza sintática, mas, sobretudo, informações de natureza semântica, para a identificação da relação que liga a oração ou o SN a informações previamente expressas no texto, e de natureza pragmática, para a compreensão das funções (argumentativas, discursivas, comunicativas) que esses constituintes exercem. No excerto (0), a relativa apositiva desgarrada exerce uma função essencialmente argumentativa, na medida em que permite ao autor chamar a atenção para seu ponto de vista (o que temos no momento são a política e as instituições), já que esse ponto de vista é duplamente realçado pelo desgarramento da sentença e, em seu interior, pela contraposição de um ponto de vista que pode ser atribuído a terceiros ou mesmo ao leitor (a política e as instituições não são perfeitas) e aquele que busca defender (mas é o que temos no momento).

É porque os constituintes desgarrados permitem colocar informações no foco de atenção do leitor ou ouvinte, como ilustra o excerto (0), que Decat (2011, p. 132-133) conceitua "o desgarramento como um mecanismo/recurso sintático que serve à estratégia de focalização, ao lado da topicalização e da clivagem”. Dessa forma, é a busca por focalizar uma informação ou um dos elementos da argumentação em curso, dando-lhe relevo, que leva o produtor do texto, tendo em vista seus propósitos comunicativos e o modo como interage com seu leitor ou ouvinte, a construir um enunciado desgarrado, apresentando-o como independente. O papel da função focalizadora no desgarramento é explicitado pela autora nestes termos:

[...] no exercício da produção textual, oral ou escrita, a função focalizadora é que irá determinar a ocorrência de uma oração como um enunciado 
independente (...); e irá determinar, também, a ocorrência dos SNs 'soltos' com objetivos comunicativos de reforçar a argumentação, de realçar ou dar destaque a determinado elemento ou a determinado fato ou situação. (DECAT, 2011, p. 133).

Desse modo, evidencia-se que, partindo dos resultados dos estudos sobre desgarramento de constituintes textuais em língua portuguesa, conduzidos na perspectiva funcionalista (em especial, Decat (2011)), a compreensão desse fenômeno pode se beneficiar de abordagem que articule informações provenientes de diferentes planos da organização do discurso.

Seguindo essa perspectiva, nosso intuito neste trabalho é evidenciar como o desgarramento de constituintes do texto pode ser estudado à luz de uma abordagem da Linguística do Texto e do Discurso, o Modelo de Análise Modular do Discurso. Desenvolvido por equipe liderada por Eddy Roulet, o modelo modular constitui uma abordagem cognitivo-interacionista para o estudo da complexidade discursiva. Para o modelo modular, o discurso, entendido como interação verbal situada, constitui uma forma de organização bastante complexa, por resultar da combinação de informações de três dimensões: linguística, textual e situacional (ROULET, 1999; ROULET; FILLIETTAZ; GROBET, 2001; FILLIETTAZ; ROULET, 2002).

Dada essa complexidade, o modelo se vale da modularidade como hipótese metodológica. Assim, do ponto de vista metodológico, o estudo da complexidade discursiva pressupõe dois movimentos. O primeiro, o de desacoplagem, implica "decompor a organização complexa do discurso em um número limitado de sistemas (ou módulos) reduzidos a informações simples" (ROULET; FILLIETTAZ; GROBET, 2001, p. 42). Os módulos considerados pelo modelo modular são o sintático e o lexical (dimensão linguística), o hierárquico (dimensão textual), o interacional e o referencial (dimensão situacional).

O segundo movimento, o de acoplagem, implica combinar as informações modulares nas formas de organização de que o discurso se compõe ou "descrever de maneira tão precisa quanto possível a forma como essas informações simples [modulares] podem ser combinadas para dar conta das diferentes formas de organização dos discursos analisados" (ROULET; FILLIETTAZ; GROBET, 2001, p. 42). Essas formas de organização são de dois tipos: elementares e complexas. As elementares (fonoprosódica ou gráfica, relacional, operacional, enunciativa, informacional, semântica, sequencial) resultam da combinação de informações extraídas dos módulos. Já as complexas (periódica, tópica, composicional, polifônica, estratégica) resultam da combinação de informações extraídas dos módulos e das formas de organização elementares e/ou complexas ${ }^{1}$.

Para uma apresentação detalhada do Modelo de Análise Modular do Discurso, cf. Roulet, Filliettaz e Grobet (2001) e Marinho (2004). 
Especificando melhor nossos objetivos neste trabalho, buscamos estender ao estudo dos constituintes desgarrados a proposta de Roulet (2004) para o tratamento dos constituintes parentéticos ${ }^{2}$. Conforme Decat (2011), os constituintes desgarrados, em particular as relativas apositivas, possuem um caráter parentético, o que se explica pelo fato de que, por meio de um constituinte desgarrado, o produtor do texto suspende momentaneamente a ação em curso (narrar, descrever, explicar, argumentar etc.), para "focalizar informações em função da argumentação" (DECAT, 2011, p. 79). Tendo em vista que Roulet (2004) estuda os constituintes parentéticos discriminando e articulando as diferentes dimensões do discurso (linguística, textual e situacional), consideramos que estender esse estudo aos constituintes desgarrados pode ajudar a identificar alguns planos da organização do discurso envolvidos no fenômeno do desgarramento, contribuindo, assim, para uma descrição e uma explicação precisas desse fenômeno.

Segundo o autor, todo constituinte parentético é uma porção textual usada pelo produtor do texto para interromper a ação em curso (por exemplo, narrar uma história) e realizar outra ação (avaliar uma parte da história, fazer um pedido a um terceiro, resolver um problema no ambiente etc.). Por esse motivo, todo constituinte parentético é um recurso linguístico com que o produtor do texto realiza uma ação que se liga às ações previamente realizadas por uma relação praxiológica de interrupção. Nesse sentido, a natureza parentética desses constituintes vem da ação descontínua (ou parentética) que eles materializam.

Mas, no interior do conjunto dos constituintes parentéticos, há um subconjunto que se caracteriza ainda por se articular ao constituinte anterior por uma relação textual, tal como a de comentário, sinalizando uma continuidade temática entre o constituinte parentético e seu contexto linguístico. Nesse caso, a complexidade desse subconjunto de constituintes parentéticos reside no fato de que à articulação de natureza praxiológica (interrupção) se acrescenta outra, mas de natureza textual. Do ponto de vista praxiológico (ou acional), eles se ligam por uma relação de interrupção às ações anteriores. Do ponto de vista textual, eles se ligam por uma relação de comentário ao constituinte anterior ${ }^{3}$.

Nessa perspectiva, Roulet (2004) propõe a existência de dois tipos de constituintes parentéticos. O primeiro se caracteriza por se articular ao constituinte anterior apenas pela relação praxiológica de interrupção. Já o segundo tipo se caracteriza por se articular ao constituinte anterior por dois tipos de relações, uma praxiológica (interrupção) e

\footnotetext{
Neste trabalho, o termo constituinte é usado para fazer referência a toda e qualquer porção de texto oral ou escrita. Assim, essa porção pode corresponder tanto a uma unidade mínima do texto (o ato), quanto a uma intervenção formada por vários atos. Para uma discussão acerca da noção de constituinte, bem como do ato enquanto única mínima de análise na abordagem modular, cf. Roulet, Filliettaz e Grobet (2001). Thompson e Couper-Kuhlen (2005) discutem a noção de clause como unidade pertinente para o estudo do papel da gramática no desenvolvimento de textos dialogais e orais.

3 Para Roulet (2002), o termo relações de discurso designa diferentes tipos de relações motivadas independentemente em planos distintos da organização do discurso. Assim, o termo recobre as relações semânticas, definidas na forma de organização semântica, as relações textuais, definidas no módulo hierárquico e na forma de organização relacional, e as relações praxiológicas, definidas no módulo referencial. Em função da importância das relações textuais e praxiológicas para a compreensão dos constituintes desgarrados, essas relações serão apresentadas de modo mais detalhado nos próximos itens.
} 
a outra textual (comentário). É o que ilustram os dois excertos abaixo, nos quais os constituintes parentéticos estão em itálico ${ }^{4}$ :

1. então chegamos à fazenda, vimos o pomar repleto de frutas e percebemos que... pode levantar um pouco o gravador? [o gravador é levantado] isso, então percebemos que as frutas ainda estavam verdes.

2. é que as pessoas se aborrecem num colóquio universitário, o que eu não entendo, e então se apressam para fazer outras coisas.

Para Roulet (2004), ambos os constituintes em itálico são parentéticos, já que ambos são porções de texto usadas pelo locutor para interromper a ação em curso e realizar outra ação localizada e momentânea (resolver um problema no ambiente - excerto (1) - ou expressar uma opinião - excerto (2)). Mas o segundo se diferencia do primeiro pelo fato de que, em (2), o constituinte parentético se liga ao cotexto por uma relação textual, o que não ocorre no primeiro. Enquanto no excerto (1) apenas a relação praxiológica de interrupção liga o constituinte em itálico ao constituinte anterior, em (2) o constituinte em itálico se liga ao anterior pela relação de interrupção e pela relação de comentário.

Porque, como observado, os constituintes desgarrados são parentéticos, este trabalho, como exposto, estende aos desgarrados a análise de Roulet (2004) para os parentéticos. Mais especificamente, nosso intuito é evidenciar que os constituintes desgarrados são constituintes parentéticos do segundo tipo proposto por Roulet (2004), ou seja, são constituintes que se ligam ao cotexto por dois tipos de relações de discurso: praxiológica (interrupção) e textual (comentário). Com essa extensão, buscamos elementos que corroborem e precisem os resultados obtidos por Decat (2011), revelando que a motivação para o desgarramento é o fato de o constituinte desgarrado constituir, ao mesmo tempo, um comentário à informação expressa anteriormente e uma interrupção (um parêntese) da ação em curso ou, em um só termo, atuar como um comentário parentético.

Neste trabalho, seguiremos um percurso de análise que estudará o fenômeno do desgarramento em três etapas. Conforme a metodologia modular, cada etapa abordará o desgarramento de constituintes do texto à luz de um módulo ou forma de organização do discurso. Na primeira, estudaremos os constituintes desgarrados do ponto de vista da forma de organização relacional, a fim de descrevermos a relação textual que liga um constituinte desgarrado a uma informação previamente abordada no texto. Na segunda etapa, analisaremos os constituintes desgarrados do ponto de vista do módulo referencial, para identificarmos a relação praxiológica que articula a ação que se realiza com o constituinte desgarrado às ações previamente realizadas. Por fim, a terceira etapa estuda os constituintes desgarrados do ponto de vista da forma de organização operacional. Nessa última etapa, os resultados das etapas anteriores (forma de organização relacional

4 Esses excertos são adaptações de textos analisados por Roulet (2004, p. 10-12). 
e módulo referencial) serão combinados, para que possamos compreender as motivações discursivas para o emprego dos constituintes desgarrados.

Nas diferentes etapas, os constituintes desgarrados que analisaremos foram extraídos de textos da mídia impressa, como reportagens e artigos de opinião. Os constituintes aqui analisados fazem parte do corpus de constituintes desgarrados que a linguista Maria Beatriz Nascimento Decat vem coletando desde 1993 e com base no qual vem realizando seus estudos sobre o tema (para uma síntese, cf. Decat (2011)). Trata-se de um corpus dinâmico, atualizado frequentemente e, por isso, de tamanho não limitado. As ocorrências nele contidas decorrem do uso da língua, na medida em que são encontradas. Desse banco de dados fazem parte dados de língua escrita (em maior número), do português brasileiro e do português europeu, coletados em jornais, revistas, trabalhos acadêmicos, propagandas, e-mails, dentre outros; também fazem parte do corpus dados de língua oral, de gêneros diversos, tais como entrevistas, conversação espontânea, relatos. Já foram coletadas, até agora, aproximadamente 1200 estruturas. Como neste trabalho nosso interesse consiste em revelar que o fenômeno do desgarramento de constituintes textuais pode ser estudado à luz do MAM, não procederemos ao tratamento quantitativo das ocorrências do corpus, o que poderá constituir a finalidade de trabalhos futuros, e optamos pelo estudo sistemático e qualitativo de apenas algumas delas.

\section{Forma de organização relacional: o constituinte desgarrado como um comentário}

A forma de organização relacional tem como objetivo estudar as relações textuais (argumento, comentário, reformulação, sucessão, topicalização etc.) que se estabelecem entre os constituintes do texto (troca, intervenção e ato) e informações previamente estocadas na memória discursiva ${ }^{5}$. Por isso, essa forma de organização resulta da combinação de informações dos módulos hierárquico (para o estudo das relações hierárquicas de dependência, independência e interdependência entre os constituintes do texto), referencial (para o estudo das relações de sentido que se estabelecem entre os constituintes do texto e informações da memória discursiva), lexical e sintático (para o estudo das marcas - conectores e estruturas sintáticas - das relações textuais). $\mathrm{Na}$ definição dessa forma de organização, é central o conceito de processo de negociação, definido no módulo hierárquico.

Nesse módulo, concebe-se a interação como um processo de negociação por meio do qual os interlocutores negociam a intencionalidade característica do encontro, com base em suas intenções individuais (ROULET, 1992) ${ }^{6}$. Como ressaltado por Roulet

\footnotetext{
A memória discursiva corresponde ao "conjunto de saberes conscientemente partilhados pelos interlocutores" (BERRENDONNER, 1983, p. 230) e abarca tanto os acontecimentos extralinguísticos como as informações sucessivamente introduzidas ao longo de um texto.

6 Por exemplo, numa livraria, a intencionalidade compartilhada por livreiro e cliente (transação de compra e venda de livros) é negociada, ao longo da interação, em função da intenção de cada um (enquanto o livreiro quer vender, o cliente quer comprar livros) (FILLIETTAZ, 2003, 2008).
} 
(1988, 1999; ROULET et al., 1985), esse processo de negociação exerce forte impacto sobre a estrutura de toda troca verbal. Para dar conta do modo como esse impacto ocorre, propõe o autor que o desenvolvimento de toda interação está submetido a dois tipos de restrições: a de completude dialógica e a de completude monológica. A restrição de completude dialógica diz respeito ao alcance do duplo acordo. Conforme Roulet (ROULET et al., 1985, p. 15),

Toda negociação tem sua origem em um problema que dá lugar a uma iniciativa do locutor; essa iniciativa pede uma reação, que pode ser favorável ou desfavorável, do interlocutor. Se ela é favorável, o locutor pode encerrar a negociação, exprimindo, por sua vez, seu acordo.

Nesse sentido, uma interação formada por uma pergunta (Que horas são?), por uma resposta (São 7 horas.) e por um agradecimento (Obrigado!) materializa uma troca completa formada por proposição (a pergunta), reação (a resposta) e ratificação (o agradecimento). Por meio dessa troca, os interlocutores alcançam o duplo acordo, concordando com o encerramento do processo de negociação.

Porém, para que a negociação possa se desenvolver, os interlocutores devem satisfazer ainda outra restrição, a de completude monológica. Essa restrição diz respeito à necessidade de que o locutor, na elaboração de determinada etapa do processo de negociação - proposição, reação ou ratificação -, elabore essa etapa de modo suficientemente adequado e completo, para que o interlocutor possa desenvolver a negociação. É a necessidade de atender à restrição de completude monológica que explica por que raramente as intervenções de cada participante de uma troca efetiva são tão simples, como as do exemplo dado no parágrafo anterior. O mais comum, como aponta Roulet (1988, 1999; ROULET et al., 1985; ROULET; FILLIETTAZ; GROBET, 2001), é as intervenções serem estruturalmente bastante complexas e uma pergunta, por exemplo, ser formada por vários atos, intervenções e mesmo trocas subordinadas.

Nessa perspectiva da interação como negociação, as relações textuais definidas na forma de organização relacional correspondem a manobras que os interlocutores realizam com o fim de atenderem às restrições de completude dialógica e monológica. Assim, fazer uma concessão, comentar partes do texto, impor condições, reformular uma informação ou sustentar um ponto de vista com argumentos são manobras que lhes permitem tentar produzir uma intervenção suficientemente adequada para a negociação em curso (CUNHA, 2017a, 2017b).

Roulet propõe dois tipos de relações textuais: as ilocucionárias, cujo estabelecimento está ligado à restrição de completude dialógica, e as interativas, cujo estabelecimento está ligado à restrição de completude monológica. As categorias de relações ilocucionárias são: iniciativas (pergunta, pedido e asserção) e reativas (resposta e ratificação) ${ }^{7}$. Já as

No modelo modular, o valor ilocucionário (pergunta, pedido, asserção etc.) caracteriza não o ato isolado, como na teoria dos atos de fala (AUSTIN, 1962; SEARLE, 1995), mas a relação que uma intervenção (formada por um ou 
categorias de relações interativas são: argumento, contra-argumento, reformulação, topicalização, tempo (sucessão), preparação, comentário, clarificação (ROULET, 2003, 2006; CUNHA, 2012a $)^{8}$.

Nessa forma de organização, a representação da maneira como os interlocutores estabelecem as relações textuais, com o fim de atenderem às restrições de completude monológica e dialógica, é feita por meio de estruturas hierárquico-relacionais. Com essas estruturas, descrevem-se as hierarquias e as relações que os constituintes do texto estabelecem com informações previamente estocadas na memória discursiva. A título de ilustração da maneira como se representa a forma de organização relacional de um texto, retomemos o excerto (2) apresentado na Introdução9:

2. (1) é que as pessoas se aborrecem num colóquio universitário, (2) o que eu não entendo, (3) e então se apressam para fazer outras coisas.

Com os dois primeiros atos, o locutor introduz argumentos que explicam por que, em um colóquio, as pessoas se apressam para fazer outras coisas, que é a informação expressa no terceiro ato. Por isso, os atos (1-2) formam uma intervenção subordinada que se liga ao ato (3) por uma relação de argumento. Na intervenção formada por (12), o locutor, por meio do ato (2), comenta a informação expressa em (1). Por isso, o ato (2) é subordinado a (1) e se liga a este por uma relação de comentário. A estrutura hierárquico-relacional presente na Figura 1 representa essa análise ${ }^{10}$.

Figura 1 - Estrutura hierárquico-relacional do excerto (2).

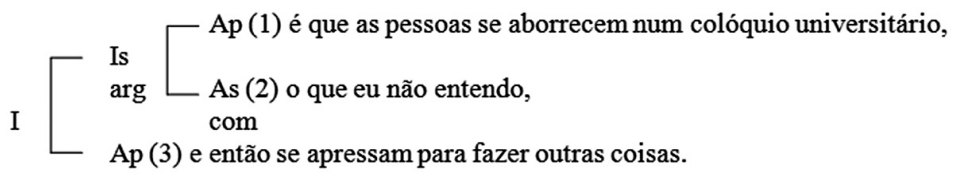

Fonte: Elaboração própria.

muitos atos, intervenções e trocas) estabelece com as informações expressas na intervenção seguinte e na intervenção anterior (ROULET, 1980, 1999; ROULET; FILLIETTAZ; GROBET, 2001).

8 As relações ilocucionárias e interativas apresentadas correspondem a categorias genéricas de relações textuais. Nesse sentido, cada relação abarca um conjunto de relações específicas. Por exemplo, a relação de argumento é uma categoria genérica que abarca as relações específicas de causa, exemplificação, argumento potencial (condição), argumento suplementar etc. A identificação dessas relações específicas se faz com base em um cálculo inferencial em que as informações de natureza linguística, textual e situacional do texto em análise constituem premissas para a obtenção da interpretação final acerca de qual relação específica liga um constituinte do texto a uma informação da memória discursiva (ROULET; FILLIETTAZ; GROBET, 2001; ROULET, 2003, 2006).

9 A numeração indica a segmentação do texto em atos.

10 Seguindo a proposta de Roulet (2004; ROULET; FILLIETTAZ; GROBET, 2001), as estruturas hierárquicorelacionais constantes deste trabalho são compostas por trocas (T), intervenções (I) e atos (A). Esses constituintes podem ser principais (p) ou subordinados (s) uns em relação aos outros. Entre os constituintes das estruturas que serão apresentadas, verificam-se as relações textuais de argumento (arg), contra-argumento (c-a), comentário (com), sucessão (suc), preparação (pre) e clarificação (cla). 
Como exposto na Introdução, nossa hipótese é a de que o desgarramento de um constituinte textual é motivado pelo fato de esse constituinte constituir, ao mesmo tempo, um comentário a algo expresso anteriormente e um recurso linguístico com que se interrompe a ação em curso. No modelo modular, a relação de interrupção é estudada no módulo referencial, de que trataremos no próximo item. Já o comentário é definido como uma relação interativa cujo fim é permitir ao produtor do texto, por meio de um constituinte hierarquicamente subordinado, realizar uma avaliação ou trazer um esclarecimento acerca de informação expressa no constituinte imediatamente anterior (CUNHA, 2016). É o que ocorre neste trecho extraído de uma reportagem sobre irregularidades no uso de dinheiro público ${ }^{11}$ :

3. (1) Em 1998, (2) mineiros e capixabas se animaram com o início da construção da BR342, (3) que ligaria o norte do Espírito Santo a Minas Gerais. (4) Para pavimentar os 106 quilômetros da rodovia, (5) foram celebrados três contratos com duas empreiteiras. (6) Nos três (7) o TCU [Tribunal de Contas da União] encontrou sobrepreço - sempre na casa de 50\% do valor global. (8) Além disso, parte dos serviços que as empreiteiras alegam ter executado não foi fiscalizada pelo governo. (9) Por fim, o valor dos contratos aumentou sem nenhuma justificativa técnica. (10) Uma estranheza atrás da outra. (11) Como a obra se tornou um sorvedouro de dinheiro público, (12) o TCU pediu sua paralisação. (13) Hoje, (14) há apenas 33 quilômetros asfaltados. (15) Outros 27 quilômetros são transitáveis, (16) mas ainda não receberam uma gota de asfalto. (17) Nos 46 quilômetros restantes, (18) a obra nem sequer foi iniciada.

Por meio da estrutura hierárquico-relacional presente na Figura 2, é possível evidenciar a relação de comentário que, no excerto (3), liga o constituinte desgarrado (ato 10) a informações previamente estocadas na memória discursiva.

Figura 2 - Estrutura hierárquico-relacional do excerto (3).

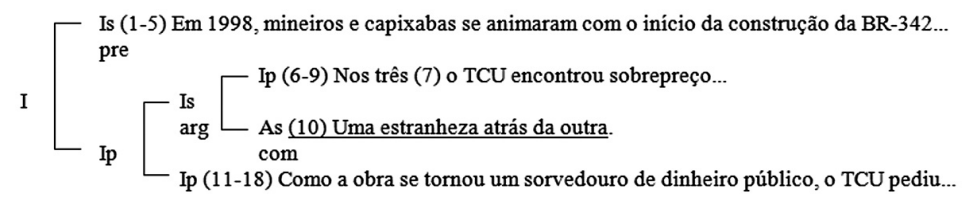

Fonte: Elaboração própria.

Como representado na estrutura, o SN desgarrado Uma estranheza atrás da outra é um ato subordinado que se liga por uma relação de comentário a informações da memória discursiva com origem na intervenção formada pelos atos (6-9), intervenção em que o jornalista apresenta os problemas ligados à construção da rodovia.

11 A reportagem de que esse trecho foi extraído se intitula "Desvios subterrâneos" e foi publicada na edição da revista Veja de 06/01/2010. Essa reportagem integra o corpus da pesquisa relatada em Cunha (2013). 
Como exposto por Decat (2011, p. 79-80), “o 'desgarramento' de certas estruturas é uma decorrência da necessidade de destacar, de focalizar informações em função da argumentação", necessidade que se explica pela busca do produtor do texto por "convencer o leitor sobre seu ponto de vista, sobre sua postura diante do tema que está desenvolvendo". Por isso, observa a autora que uma das características dos constituintes desgarrados é exercerem a função de avaliação ${ }^{12}$. A nosso ver, é o que ocorre no excerto (3). Nele o jornalista, após apresentar as irregularidades ligadas à construção da rodovia, faz uma avaliação dessas irregularidades no ato (10), expressando seu ponto de vista sobre a questão e, por isso mesmo, tentando convencer o leitor desse ponto de vista. Nesse sentido, o jornalista liga o ato (10) aos problemas relativos à construção da rodovia, mencionados por ele em (6-9), por meio de uma relação de comentário. Do ponto de vista da função que os constituintes desgarrados exercem, essa natureza avaliativa é inerente ao fenômeno do desgarramento de modo geral, independentemente da natureza sintática do constituinte desgarrado, como evidencia a oração relativa apositiva presente no excerto (0), apresentado na Introdução e reproduzido a seguir.

0. (1) A democracia representativa falhou em garantir o respeito aos anseios de sociedades plurais e complexas. (2) Isso não significa, por outro lado, que a solução seja negar a política e suas instituições. (3) Que podem não ser perfeitas, (4) mas é o que temos neste momento.

Nesse excerto, com a relativa apositiva desgarrada (atos 3-4), o autor faz um comentário sobre a informação "a política e suas instituições", expressa no ato (2). Porém, com esse comentário, o autor, mais do que introduzir uma informação factual sobre a política e as instituições brasileiras, avalia essa mesma informação.

No próximo item, abordaremos o caráter parentético e avaliativo dos constituintes desgarrados à luz do módulo referencial.

\section{Módulo referencial: o constituinte desgarrado como uma unidade acional parentética}

No modelo modular, a finalidade do módulo referencial é descrever as relações que o discurso mantém com o mundo ou o contexto no qual é produzido, bem como as

\footnotetext{
12 Em seu estudo dos parênteses, Jubran (2006, p. 326-356) propõe uma categorização funcional dos parênteses, considerando "o foco sobre o qual incidem predominantemente os fatos de parentetização" (p. 326). Assim, os parênteses se distribuem entre os que focalizam i) a elaboração tópica do texto, ii) o locutor, iii) o interlocutor e iv) o ato comunicativo. Cada uma dessas classes de parênteses exerce diferentes funções. Por exemplo, os parênteses que podem ser classificados como focalizadores da elaboração tópica exercem as funções de exemplificação, esclarecimento, ressalva, retoque e correção (cf. quadro-síntese em Jubran (2006, p. 327)). Ainda que este trabalho não tenha a intenção de aproximar os estudos sobre estruturas desgarradas do estudo sobre as funções dos parênteses, conduzido por Jubran (2006), o que pode constituir o objetivo de estudo futuro, é possível aventar que a natureza essencialmente avaliativa dos constituintes desgarrados faz com que eles possam exercer basicamente as funções de esclarecimento e de avaliação do ato comunicativo. Tem-se, assim, um horizonte de pesquisa interessante para o refinamento de nossa percepção de que os constituintes desgarrados exercem uma função geral de avaliação.
} 
relações que o discurso mantém com o(s) mundo(s) que representa. Conforme Roulet (1996, p. 22), "esses mundos podem ser analisados em representações mentais de tipo praxiológico, para as ações, e de tipo conceitual, para os seres e as coisas”. Assim, esse módulo busca dar conta, de um lado, das ações verbais e não verbais realizadas ou designadas pelos interlocutores e, de outro lado, dos conceitos ativados em tais ações.

Tendo em vista os objetivos deste trabalho, abordaremos apenas a maneira como, no módulo referencial, se estudam as ações verbais e não verbais efetivamente realizadas em uma interação. Para realizar esse estudo, o modelo propõe a estrutura praxiológica, instrumento de análise com o qual se representam os percursos acionais realizados pelos interlocutores.

Nos estudos da linguagem, as ações são tradicionalmente abordadas com o aporte da teoria dos atos de fala, que, embora mostre que dizer é fazer, permanece essencialmente ligada à linguagem verbal (AUSTIN, 1962; SEARLE, 1995). Porém, a complexidade das nossas interações resulta, em grande medida, do fato de que nelas realizamos não só ações verbais (pedir, convidar, ordenar), mas também ações não verbais (pegar e dar objetos, apontar elementos do ambiente, reorientar o curso das ações). Por isso, o desenvolvimento de uma interação implica frequentemente um conjunto complexo de condutas sequencial e hierarquicamente organizadas (FILLIETTAZ, 1997, 2000, 2004). Para descrever o caráter sequencial e hierárquico das condutas, a estrutura praxiológica representa as unidades acionais que participam de sua construção, bem como as relações por meio das quais as unidades se ligam em diferentes níveis da estrutura.

As unidades acionais que participam da construção da estrutura praxiológica são, em ordem decrescente, a incursão, a transação, o episódio, a fase e a ação mínima.

A incursão constitui a unidade praxiológica máxima e é formada pela totalidade das ações realizadas numa interação. Um exemplo de incursão pode ser um debate eleitoral completo ou o conjunto das condutas ligadas à transação de compra e venda de livro numa livraria (FILLIETTAZ, 1997, 2000).

A transação, unidade constitutiva da incursão, é formada pelas condutas ligadas a um foco central ou "objeto transacional" (FILLIETTAZ, 2000). Em um debate eleitoral, a transação é o conjunto das condutas ligadas à discussão de cada temática (educação, saúde, trabalho, mobilidade urbana). Em uma livraria, é o conjunto das condutas ligadas, por exemplo, à encomenda de um livro.

O episódio e a fase são unidades intermediárias que dão conta da estruturação hierárquica das condutas que formam a transação. Em outros termos, são as sequências de ações constitutivas de uma transação. Em um debate, é o conjunto das ações envolvidas na elaboração das perguntas, respostas, réplicas e tréplicas de cada candidato. Já em uma livraria, é, por exemplo, o procedimento de solicitação de um livro, com o qual o cliente dá início à transação de encomenda.

A ação mínima constitui a menor unidade praxiológica e é "guiada cognitivamente por um objetivo ou uma intenção e potencialmente identificável como tal por um coagente" (ROULET; FILLIETTAZ; GROBET, 2001, p. 121). Em um debate eleitoral, são o cumprimento, as críticas, as promessas, as consultas a material impresso etc. Em 
uma livraria, são o pagamento, o agradecimento, a despedida, a retirada de um livro da estante, a entrega do troco etc.

Essas unidades praxiológicas se ligam em diferentes níveis da estrutura por meio de três categorias de relações: etapa, reorientação e interrupção. A de etapa indica que um objetivo determinado está sendo executado. A de reorientação indica que o objetivo em execução foi mal sucedido, levando os interlocutores a uma reorientação local ou global da interação. A relação de interrupção indica o abandono momentâneo ou definitivo de um objetivo (ROULET; FILLIETTAZ; GROBET, 2001).

Como exposto na Introdução, Roulet (2004), ao tratar dos constituintes parentéticos, os define como constituintes com os quais o produtor do texto interrompe a ação em curso para realizar uma ação localizada e momentânea. Em outros termos, o que dá a esses constituintes sua natureza parentética é o fato de serem recursos usados para materializar (textualizar) uma unidade acional descontínua ou que interrompe a ação em curso. Assim, do ponto de vista praxiológico, um constituinte é considerado parentético, se ele corresponde a uma unidade acional que se liga à unidade anterior por uma relação de interrupção.

Definição semelhante dos parênteses é proposta por Berrendonner (2008). Para o autor, os parênteses constituem "sequências intercaladas em posição mediana em uma configuração textual do tipo [A A $_{1}$ [IP] $A_{2}$ ]" (BERRENDONNER, 2008, p. 7), em que $\mathrm{A}_{1}$ é uma unidade comunicativa inacabada ("enunciação de uma clause incompleta, ou estrutura periódica interrompida"), $\mathrm{A}_{2}$ é uma unidade que dá sequência à construção iniciada em $A_{1}$ e IP (inserção parentética) é "uma sequência intercalar exógena". Conforme o autor, a natureza intercalar e exógena da IP se manifesta seja em sua autonomia sintática de unidade não integrável à estrutura $\left[\mathrm{A}_{1} \ldots \mathrm{A}_{2}\right]$, seja no fato de promover a interrupção do texto em processo de construção $\left(\mathrm{A}_{1}\right)$, implicando, em textos orais, fenômenos bem descritos em especial pelos estudiosos da Análise da Conversação (SCHEGLOFF, 2007), tais como backtracking, anacolutos, restart prosódico ou mesmo o abandono da construção iniciada em $\mathrm{A}_{1}$.

A inserção de um elemento parentético numa estrutura $\left[A_{1} \ldots A_{2}\right]$ ocorre no excerto (1), apresentado na Introdução e reproduzido a seguir, em que o constituinte parentético pode levantar um pouco o gravador? [o gravador é levantado] isso - corresponde a uma fase de um episódio em que o entrevistado realiza a ação de narrar a ida ao pomar de uma fazenda ${ }^{13}$.

1. (A) então chegamos à fazenda, (B) vimos o pomar repleto de frutas $(\mathrm{C})$ e percebemos que... (D) pode levantar um pouco o gravador? (E) [o gravador é levantado] (F) isso, $(\mathrm{G})$ então percebemos que as frutas ainda estavam verdes.

Por meio da estrutura praxiológica presente na Figura 3, representamos a maneira como as ações se articulam hierarquicamente no episódio:

13 As letras indicam a segmentação do texto em ações mínimas. 
Figura 3 - Estrutura praxiológica do excerto (1).

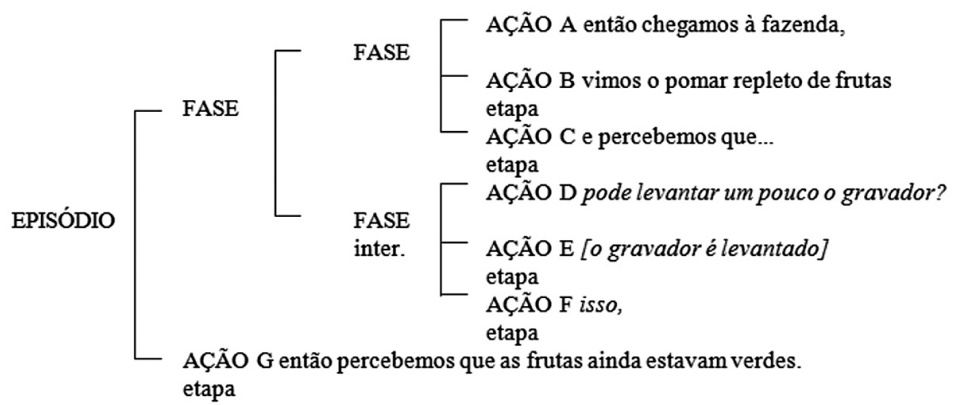

Fonte: Elaboração própria.

As três ações mínimas D (pedido), E (atendimento do pedido) e F (ratificação do pedido) constituem uma fase com a qual os interlocutores resolvem um problema para a entrevista. Essa fase se liga à anterior pela relação de interrupção, porque, por meio dela, o entrevistado suspende a ação $\mathrm{C}$, em que havia começado a narrar a complicação da história, ação que será retomada após o fim do parêntese, na ação G. Conforme essa interpretação, a fase formada pelas ações (D-F) promove uma interrupção momentânea e não definitiva da fase que vinha sendo realizada, porque, resolvido o problema que motivou a interrupção (a posição do gravador), um dos interlocutores, o entrevistado, dá continuidade à ação de narrar.

A definição de parêntese como a inserção interruptiva de uma unidade acional em uma unidade acional mais ampla está em consonância com a definição de parêntese proposta por Jubran (2006). Ainda que se baseie em arcabouço teórico distinto do nosso e busque dar conta da inserção de unidades tópicas, problemática que, no modelo modular, se estuda na forma de organização tópica, a autora também entende que, no processo de inserir um parêntese (parentetização), o locutor promove a suspensão/ interrupção momentânea do tópico em curso para inserir de forma pontual um (sub) tópico. Em sua definição de parêntese,

[...] o elemento inserido provoca uma breve suspensão do tópico no qual se encaixa, de modo que não ocorre a cisão desse tópico em porções textuais nitidamente separáveis, porque a sua interrupção é momentânea e a retomada é imediata. Teríamos, então: tópico A (suspensão momentânea do tópico A) continuidade do tópico A (JUBRAN, 2006, p. 302-303).

No plano praxiológico da organização do discurso, entendemos que o mesmo fenômeno ocorre quando se emprega um constituinte desgarrado. Nesse plano, a ação de introduzir um constituinte desgarrado num determinado ponto do texto corresponde à ação de interromper uma ação em curso para realizar outra ação de forma localizada 
e momentânea. É essa natureza interruptiva dos constituintes desgarrados que, na perspectiva modular adotada neste trabalho, nos permite entendê-los como parentéticos.

Ao mesmo tempo, é essa mesma natureza interruptiva desses constituintes que explica por que o desgarramento, como observa Decat (2011), é um dos recursos sintáticos por meio dos quais é possível realizar a estratégia de focalização. Afinal, é necessário interromper a ação que se está realizando, para melhor colocar no foco de atenção do leitor ou ouvinte determinada informação, realçando-a. Não por acaso, Berrendonner (2008), em sua definição dos parênteses exposta acima, nota que a inserção parentética corresponde a uma unidade caracterizada pela autonomia sintática. Os enunciados desgarrados são autônomos não só sintaticamente, mas ainda prosodicamente no texto oral (pausa antecedendo o enunciado e contorno entonacional de princípio e de fim de unidade (DECAT, 2011, p. 128)) e graficamente no texto escrito (enunciado antecedido por ponto final e iniciado por letra maiúscula) (DECAT, 2011, p. 115).

A natureza parentética ou interruptiva dos constituintes desgarrados se evidencia no excerto (3), analisado no item anterior. Nele, o jornalista o inicia narrando que a construção da BR-342, que ligaria no norte do Espírito Santo a Minas Gerais, motivou a celebração de três contratos com duas empreiteiras $(1-5)^{14}$. Dando sequência a essa narração, ele introduz a complicação da história, ao informar que três irregularidades foram identificadas pelo TCU nas obras: sobrepreço, falta de fiscalização pelo governo e aumento no valor dos contratos (6-9). Nesse ponto do texto, o jornalista suspende a narração para expressar, no ato (10), sua opinião (avaliação) sobre esses mesmos casos (Uma estranheza atrás da outra). Realizada essa ação, o jornalista retoma a narração, informando como o TCU agiu diante dos problemas e o estado da rodovia no momento da escrita/veiculação da reportagem (11-17). Essa análise praxiológica pode ser representada por meio da Figura 4:

Figura 4 - estrutura praxiológica do excerto (3).

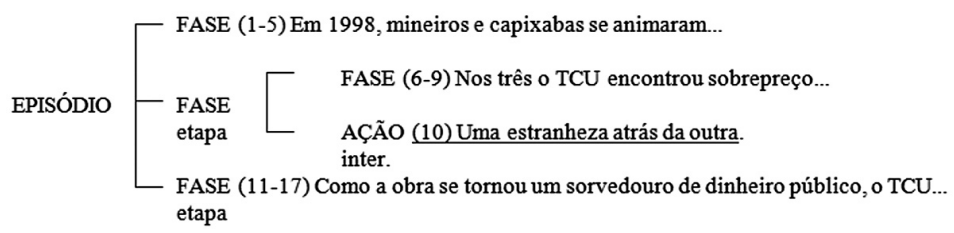

Fonte: Elaboração própria.

Como evidencia essa estrutura, a natureza parentética do SN desgarrado Uma natureza atrás da outra vem, assim, do fato de que, ao produzi-lo, o jornalista promove uma interrupção ou uma suspensão da narração em curso. Com o SN desgarrado, ele

14 A numeração constante do excerto (3) se refere aos atos textuais, definidos no módulo hierárquico. Mas, para facilitar a leitura da estrutura praxiológica (Figura 4), utilizaremos a mesma numeração para fazer referência às ações mínimas (módulo referencial) de que o excerto se compõe. 
suspende a narração para, abrindo um parêntese, revelar ao leitor o caráter estranho ou suspeito dessas irregularidades. Feita a avaliação, o autor pode retomar a ação de narrar, expressando as medidas tomadas pelo TCU - atos 11-12 - e a situação da rodovia no momento da escrita/veiculação da matéria - atos 13-17.

No próximo item, descreveremos, por meio da combinação das estruturas hierárquico-relacional e praxiológica, o papel conjunto desses diferentes planos da organização do discurso na ocorrência de constituintes desgarrados.

\section{Forma de organização operacional: o constituinte desgarrado como um comentário parentético}

No modelo modular, a forma de organização operacional tem por finalidade descrever um domínio específico da complexidade das produções discursivas, que é o da articulação entre as ações e a linguagem verbal. Dependendo das características do contexto em que estamos inseridos, podemos realizar uma mesma ação, como, por exemplo, cumprimentar, por meio de diferentes meios semióticos. Assim, podemos cumprimentar usando um ato de fala (Tudo bem?), um aceno de mão, um sorriso acompanhado de um meneio de cabeça ou um emoji. Desse modo, das múltiplas decisões que precisamos tomar, quando interagimos, uma é a escolha de como semiotizar nossas ações, em função das restrições impostas pelo contexto (FILLIETTAZ, 2004, 2011). Por isso, uma das causas da complexidade de nossas interações é a profunda complementaridade entre as ações e os recursos semióticos (verbais, gestuais, imagéticos etc).

Em uma abordagem que se ocupa da complexidade da organização discursiva, como o modelo modular, o estudo dessa complementaridade se faz na forma de organização operacional, que resulta da articulação de dois planos da organização do discurso: a estrutura hierárquico-relacional e a estrutura praxiológica. Estudadas separadamente nos itens anteriores, essas estruturas, quando combinadas, permitem "especificar a natureza das relações que os processos acionais mantêm com as formas semióticas complexas que os mediatizam" (ROULET; FILLIETTAZ; GROBET, 2001, p. 210). Nesse sentido, a combinação dessas estruturas é uma das maneiras pelas quais o modelo modular estuda a multimodalidade (ou pluricanalidade) própria das produções discursivas (ROULET; FILLIETTAZ; GROBET, 2001).

Para mostrar a maneira como as ações e diferentes recursos semióticos se combinam em uma mesma produção discursiva, realizaremos a análise da forma de organização operacional do excerto (1), cuja estrutura praxiológica foi descrita no item anterior. A figura 5 constitui o resultado da análise da forma de organização operacional do excerto. Nela vemos, à esquerda, a estrutura praxiológica e, à direita, a estrutura hierárquico-relacional ${ }^{15}$.

15 Essa estrutura apresenta semelhanças parciais com a estrutura operacional proposta por Roulet (2004, p. 11). 
Figura 5 - Estrutura operacional do excerto (1).
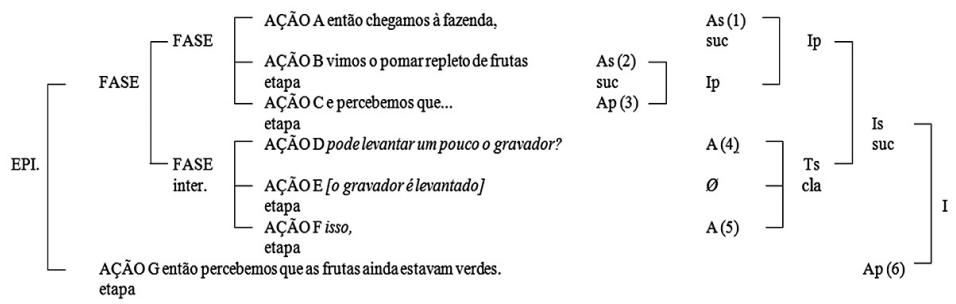

Fonte: Elaboração própria.

Com a estrutura operacional, verifica-se que, nesse excerto, os interlocutores realizam as ações não só por meio da linguagem verbal, mas também por gestos. Assim, enquanto o entrevistado se vale apenas da linguagem verbal, o entrevistador, que é o responsável pela gravação, realiza nesse trecho apenas uma ação não verbal (ação E: levantar o gravador). Entendendo que a pergunta feita no ato (4) pelo entrevistado é um pedido indireto, o entrevistador reage ou "responde", realizando a ação de levantar o gravador. Desse modo, essa estrutura permite uma descrição da sincronia entre ações verbais e não verbais que caracteriza grande parte das interações efetivas.

Com essa estrutura, verifica-se ainda que a fase por meio da qual o locutor interrompe a ação que vinha realizando (narrar) para resolver um problema pontual (reparar a altura do gravador) (fase formada pelas ações D-F) se textualiza na troca formada pelos atos (4-5), a qual é subordinada à intervenção que expressa os eventos iniciais da história e que é formada pelos atos (1-3). Entendemos que essa troca se liga à intervenção principal (1-3) por uma relação de clarificação, já que, por meio dela, os interlocutores resolvem conjuntamente um problema que, para o locutor, poderia comprometer a clareza (a completude monológica) de sua intervenção ${ }^{16}$.

Conforme Roulet (2004), a estrutura operacional constitui um instrumento de análise bastante eficaz para descrever não só o papel de constituintes não verbais, como a ação $\mathrm{E}$ (levantar o gravador), mas também o papel de constituintes parentéticos, que, segundo ele, têm resistido a uma análise estritamente linguística e textual. Como mostra a Figura 5, o constituinte em itálico (ações D-F) não faz parte da narração, já que ele constitui, do ponto de vista relacional (estrutura à direita), uma troca subordinada cuja função é resolver um problema para a clareza da narração e, do ponto de vista referencial (estrutura à esquerda), uma fase que interrompe momentaneamente a ação em curso. Assim, o que dá a esse constituinte seu caráter parentético é, ao mesmo tempo, sua natureza de constituinte textual subordinado e de unidade acional descontínua.

Já que os constituintes desgarrados, conforme apontado por Decat (2011), possuem uma natureza parentética, entendemos que a estrutura operacional também constitui

16 Nesse ponto, nossa interpretação se difere da de Roulet (2004). Como informamos na Introdução, para o autor, essa troca não estabeleceria qualquer relação de natureza textual com a intervenção anterior. A única relação que caracterizaria o constituinte em itálico seria a relação praxiológica de interrupção. 
um instrumento de análise adequado para a descrição e explicação das especificidades desses constituintes e de seu uso. Para evidenciar o papel da estrutura operacional na compreensão de constituintes desgarrados, propomos a seguir a estrutura operacional do excerto (3), em que são narradas irregularidades na construção da BR-342. Nos itens anteriores, analisamos separadamente as estruturas hierárquico-relacional (Fig. 2) e praxiológica (Fig. 4) desse fragmento. A estrutura operacional presente na Figura 6 resulta da combinação dessas duas estruturas.

Figura 6 - Estrutura operacional do excerto (3).

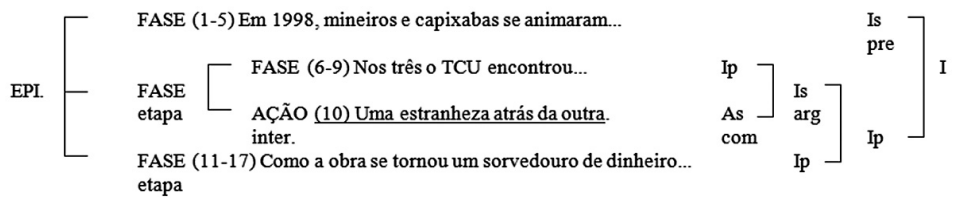

Fonte: Elaboração própria.

Por meio dessa estrutura, verifica-se que o jornalista, para expressar sua opinião sobre as irregularidades, interrompe a narração, valendo-se do SN desgarrado, o ato (10). Assim, a natureza parentética desse constituinte desgarrado se explica pelo fato de ele constituir uma unidade acional que interrompe uma ação em curso. É provável que, se, do ponto de vista praxiológico, o constituinte desgarrado não interrompesse a ação em curso, o desgarramento não se verificasse. É o que ocorre, por exemplo, no ato (3) do mesmo excerto:

4. (1) Em 1998, (2) mineiros e capixabas se animaram com o início da construção da BR-342, (3) que ligaria o norte do Espírito Santo a Minas Gerais. (...)

Do ponto de vista textual, o ato (3) se liga ao (2) por uma relação de comentário. Porém, do ponto de vista praxiológico, a ação que o jornalista realiza por meio do ato (3) não interrompe a ação iniciada com o ato (2). Informar que a BR-342 ligaria o norte do Espírito Santo a Minas Gerais (ato 3) constitui uma etapa para a realização da ação de informar que mineiros e capixabas se animaram com o início da construção dessa rodovia (ato 2) e não uma interrupção dessa ação de informar. Diferentemente do modo como emprega o ato (2), o jornalista, com o ato (10), suspende a ação em curso (narrar) para realizar outra ação (avaliar). O ponto final que separa o ato (10) do cotexto à esquerda pode ser entendido como uma marca gráfica dessa interrupção realizada no plano praxiológico.

Nessa perspectiva, a função de enfatizar ou destacar informações que diferentes autores associam aos constituintes parentéticos (FORGET, 2000; ROULET, 2004; JUBRAN, 2006) e que Decat (2011) associa aos constituintes desgarrados parece se explicar pelo fato de que, na estrutura praxiológica, esses constituintes interrompem 
a ação em curso, levando o leitor ou ouvinte a se deter na ação interruptiva. Por essa razão, como aponta Forget (2000) para as inserções parentéticas, não há contradição em afirmar que um constituinte parentético e, no que nos interessa, desgarrado se caracteriza, ao mesmo tempo, por ser subordinado e por destacar ou enfatizar uma informação. Como bem evidencia a estrutura operacional, o constituinte desgarrado, no plano textual, se liga ao cotexto por uma relação de comentário, sendo, por isso, subordinado; no plano praxiológico, esse mesmo constituinte se liga por uma relação de interrupção às ações previamente realizadas, fazendo, por isso, com que a informação nele expressa ganhe destaque.

Para tornar mais evidentes os elementos de diferentes planos do discurso implicados na ocorrência de constituintes desgarrados, analisaremos outro excerto. Neste trecho de um artigo de opinião (DIMENSTEIN, 2011), a intervenção formada pelos atos (9-11) constitui uma relativa apositiva desgarrada ${ }^{17}$.

5. (01) É um crime

(02) A divulgação da lista das faculdades que não aprovaram nenhum aluno no exame da OAB é apenas o lado ainda mais escandaloso de um escândalo: (03) jovens passam anos pagando mensalidades (04) (em geral vindos de famílias mais pobres) (05) e, no final, têm de jogar o diploma fora. (06) Deveria ser um crime contra o direito do consumidor.

(07) O escândalo maior é que a maioria não passa, (08) cerca de $90 \%$ dos candidatos. (09) $\underline{\mathrm{O} \text { que revela um drama educacional geral, (10) desde o ensino básico, (11) agravando-se }}$ na faculdade. (12) É gente que sequer sabe ler um texto direito. (13) Muitas faculdades são obrigadas a dar aulas de português.

(14) O escândalo poderia ser ainda maior (15) se todas as profissões exigissem semelhante exame ao do OAB. (16) Os poucos que existem - medicina, por exemplo - já são uma tragédia. (...)

A estrutura operacional desse excerto pode ser representada por meio da Figura 7:

Figura 7 - estrutura operacional do excerto (5).

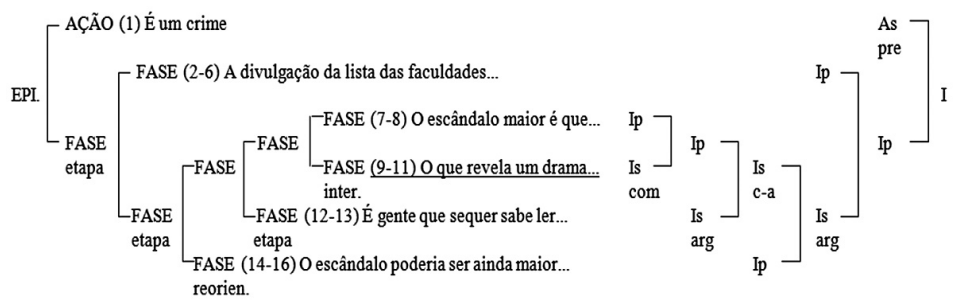

Fonte: Elaboração própria.

17 O texto completo, de autoria de Gilberto Dimenstein, foi analisado do ponto de vista relacional em Cunha (2012b). 
No plano textual (estrutura hierárquico-relacional à direita), o constituinte formado pelos atos (9-11) é uma intervenção subordinada, que se liga à intervenção (7-8) por uma relação de comentário. Isso porque, com o constituinte subordinado, o autor faz um comentário sobre a formação dos estudantes mencionados na intervenção (7-8) (para o autor, a causa do resultado do exame da OAB é a existência de um problema “drama" - educacional geral). No plano acional (estrutura praxiológica à esquerda), o mesmo constituinte desgarrado é o meio semiótico escolhido pelo autor para realizar uma fase (expressar sua opinião sobre a formação dos estudantes) que se liga à fase anterior (denunciar o índice elevado de reprovações) por uma relação de interrupção, já que, ao abordar os problemas de formação dos estudantes (9-11), o autor suspende a ação de denunciar o resultado insatisfatório desses estudantes no exame da OAB (7-8), ação que o autor retoma a partir do ato (12).

Assim como no excerto (3), analisado anteriormente, o que motiva o desgarramento da relativa apositiva formada pelos atos (9-11) no artigo "É um crime" parece ser o fato de o autor, em sua busca por chamar a atenção do leitor para a avaliação expressa nesse constituinte desgarrado, fazer desse constituinte, ao mesmo tempo, um comentário e uma interrupção ou, em um único termo, um comentário parentético.

A nosso ver, é essa natureza ambivalente dos constituintes desgarrados, natureza que a estrutura operacional permite evidenciar, que os torna uma estratégia de formulação textual fortemente argumentativa e complexa. Assim como ocorre com os demais constituintes parentéticos que se caracterizam pela dupla relação de comentário e de interrupção (FORGET, 2000; ROULET, 2004), o locutor, ao empregar um constituinte desgarrado, pode apresentar esse constituinte, ao mesmo tempo, como dispensável, por se materializar como um simples comentário (é um efeito da estrutura textual), e como indispensável, por interromper o percurso acional, chamando a atenção do interlocutor para as informações nele expressas (é um efeito da estrutura praxiológica).

A natureza duplamente comentativa/avaliativa e interruptiva/parentética dos constituintes desgarrados encontra uma evidência suplementar em textos escritos nos quais o constituinte parentético ocorre entre parênteses, como no excerto (6), em que o enunciado desgarrado é uma adverbial concessiva.

6. A forma escrita descontextualiza a piada, priva-a de boa parte de sua força emocional, do privilégio e da proteção do grupo fechado. Apenas quando nos imaginamos nas circunstâncias originais e nos lembramos de nossa humanidade comum, é que podemos apreciar a maioria dessas antigas piadas. (Muito embora eu tenha passado pela experiência de tentar demonstrar fragilidade de uma dessas piadas velhas, contando-a a um grupo, o que resultou em gargalhada geral.) O leitor solitário pode imaginar-se no grupo, mas também pode colocar-se como o estranho, caso em que a piada pode ofender quando, originalmente, não havia essa intenção. (BREWER, 2000).

Nesse excerto, os parênteses sinalizam de forma ainda mais evidente a interrupção de uma ação em curso (realizar uma exposição teórica sobre a piada) para realizar outra (expressar uma experiência/avaliação pessoal). O autor apresenta a outra ação, 
materializada ou textualizada na adverbial concessiva, ao mesmo tempo, como acessória (ele realiza um comentário pessoal inserido numa exposição mais ampla) e indispensável (ele destaca/focaliza a informação pelo uso combinado do ponto final antecedendo a oração, da letra maiúscula que a inicia, dos parênteses e da passagem da $1^{\mathrm{a}}$ pessoa do plural - "podemos apreciar" - para a $1^{\text {a }}$ do singular - "eu tenha passado", implicandose no texto (BRONCKART, 2007)).

\section{Considerações finais}

Com o estudo dos constituintes desgarrados, nosso objetivo foi o de evidenciar a natureza complexa do fenômeno. Mais do que um fenômeno sintático, o desgarramento de constituintes do texto é um procedimento de formulação textual que envolve ainda os planos relacional e praxiológico do discurso. Para evidenciar a complexidade do fenômeno, este trabalho estendeu aos constituintes desgarrados o tratamento dado por Roulet (2004) aos constituintes parentéticos, tratamento feito com base em instrumentos do Modelo de Análise Modular do Discurso. Para o autor, um constituinte parentético sempre se caracteriza, no plano praxiológico, por uma relação de interrupção e pode ou não se caracterizar, no plano textual, por uma relação de comentário.

Estendendo essa proposta aos constituintes desgarrados, trouxemos evidências, por meio da combinação de estruturas próprias de planos distintos da organização do discurso (as estruturas hierárquico-relacional e praxiológica), de que eles são empregados com a dupla função de comentar algo e interromper uma ação em curso. Nesse sentido, a complexidade dos constituintes desgarrados está no fato de que eles se ligam a informações previamente estocadas na memória discursiva por duas categorias de relações: uma textual (comentário) e uma praxiológica (interrupção).

É essa dupla função dos constituintes desgarrados que dá a eles a natureza ambivalente apontada ao final do item anterior. Quando se vale de um constituinte desgarrado (SNs, relativas apositivas ou orações adverbiais), o locutor apresenta a informação expressa nesse constituinte como acessória ou subsidiária, porque, na estrutura hierárquico-relacional, o constituinte corresponde a um ato ou intervenção subordinada que se liga a uma informação do texto por uma relação de comentário. Ao mesmo tempo, com esse mesmo constituinte, o locutor apresenta a informação nele expressa como essencial e indispensável. Isso porque, na estrutura praxiológica, a introdução dessa informação leva à interrupção do percurso acional, o que obriga o interlocutor a focalizar sua atenção nessa informação.

Nessa perspectiva, uma motivação importante para a ocorrência de constituintes desgarrados reside na possibilidade que esses constituintes oferecem ao produtor do texto, enquanto estratégia argumentativa, de focalizar uma informação relevante (estrutura praxiológica), sem colocá-la explicitamente como objeto de discussão (estrutura hierárquico-relacional). É essa possibilidade que parece explicar a produtividade de desgarradas, atestada por Decat (2011), em gêneros marcados pela polêmica e pelo embate de ideias, como artigos de opinião, editoriais e entrevistas. 
CUNHA, G.; DECAT, M. For a characterization of detached textual constituents as parenthetic comments based on a modular perspective of the discourse organization. Alfa, São Paulo, v. 65, 2021 .

- ABSTRACT: For Decat (2011), the unattachment of constituents corresponds to structures that occur freely, without being syntactically linked to a clause or any other textual portion. In this paper, we show that constituent unattachment can be studied in the framework of the Modular Approach to Discourse Analysis. More specifically, we extend to the study of unattached constituents Roulet's (2004) proposal for the treatment of parenthetic constituents. In this paper, we will study the phenomenon of unattachment in three stages. In the first, we will study the textual relationship that links an unattached constituent to information previously expressed in the text. In the second step, we will analyze the action relation that articulates the unattached constituent to the previously performed actions. Finally, the third stage studies unattached constituents from the point of view of the operational organization form. In this last stage, the results of the previous stages will be combined to understand the discursive motivations of the unattachment. In the different stages, the unattached constituents that we will analyze were extracted from media texts, such as reports and opinion articles.

- KEYWORDS: Detached constituents. Parenthetic constituents. Modularity.

\section{REFERÊNCIAS}

AUSTIN, J. L. How to do things with words. Oxford: Clarendon Press, 1962.

BERRENDONER, A. Pour une praxéologie des parenthèses. Verbum, Paris, n.30, p. 5-23, 2008.

BERRENDONER, A. Connecteurs pragmatiques et anaphore. Cahiers de linguistique française, Genebra, n.5, p. 215-246, 1983.

BREWER, D. Livros de piada em prosa predominantes na Inglaterra entre os séculos XVI e XVIII. In: BREMMER, J.; ROODENBURG, H. (org.). Uma história cultural do humor. Rio de Janeiro: Record, 2000. p. 133-163.

BRONCKART, J. P. Atividade de linguagem textos e discursos: por um interacionismo sócio-discursivo. São Paulo: EDUC, 2007.

CUNHA, G. X. Conectores e processo de negociação: uma proposta discursiva para o estudo dos conectores. Fórum Linguístico, Florianópolis, n.14, p. 1699-1716, 2017a.

CUNHA, G. X. O papel dos conectores na co-construção de imagens identitárias: o uso do mas em debates eleitorais. Alfa, Araraquara, n.61, p. 599-623, 2017 b.

CUNHA, G. X. Relações de discurso em narrativas jornalísticas: em busca de sistematizações. Filologia e Linguística Portuguesa, São Paulo, n.17, p. 641-673, 2016. 
CUNHA, G. X. A construção da narrativa em reportagens. 2013. 601 f. Tese (Doutorado em Linguística) - Faculdade de Letras, Universidade Federal de Minas Gerais, Belo Horizonte, 2013.

CUNHA, G. X. Uma proposta para o tratamento das relações de discurso temporais no Modelo de Análise Modular do Discurso. Revista do GEL, Campinas, n.9, p. 2949, $2012 \mathrm{a}$.

CUNHA, G. X. A articulação discursiva do gênero artigo de opinião à luz de um modelo modular de análise do discurso. Filologia e Linguística Portuguesa, São Paulo, n.14, p. 73-97, 2012 b.

DECAT, M. B. N. Estruturas desgarradas em Língua Portuguesa. Campinas: Pontes, 2011.

DIMENSTEIN, G. É um crime. Folha de S. Paulo, São Paulo, 2011. Disponível em: http://www1.folha.uol.com.br/colunas/gilbertodimenstein/939263-e-um-crime.shtml. Acesso em: 21 maio 2021.

FILLIETTAZ, L. Asking questions... getting answers. Pragmatics and Society, Nova York, v.2, n.2, p. 234-259, 2011.

FILLIETTAZ, L. La co-construction des requêtes. Le cas du service à la clientèle dans les grandes surfaces. In: KERBRAT-ORECCHIONI, C.; TRAVERSO, V. (org.). Les interactions en site commercial: invariants et variations. Lyon: Ens Éditions, 2008. p. 77-103.

FILLIETTAZ, L. Négociation, textualisation et action: le concept de négociation dans le modèle genevois de l'organisation du discours. In: GROSJEAN, M.; MONDADA, L. (org.). La négociation au travail. Lyon: Presses universitaires de Lyon, 2004. p. 69-96.

FILLIETTAZ, L. Textualisation et cadrage des activités: une analyse praxéologique des interactions de service. In: MARI, H. et al. (org.). Análise do discurso em perspectivas. Belo Horizonte: Faculdade de Letras da UFMG, 2003. p. 179-213.

FILliETTAZ, L. Actions, activités et discours. 2000. 403f. Tese (Doutorado em Linguística) - Faculdade de Letras, Universidade de Genebra, Genebra, 2000.

FILLIETTAZ, L. Des enjeux actionnels dans les interactions verbales: une définition de la dimention référentielle du discours. Cahiers de linguistique française, Genebra, n.19, p. 47-82, 1997.

FILliETTAZ, L.; ROULET, E. The Geneva Model of discourse analysis: an interactionist and modular approach to discourse organization. Discourse Studies, Thousand Oaks, v.4, n.3, p. 369-392, 2002.

FORGET, D. Les insertions parenthétiques. Revue québéciose de linguistique, Montreal, v.28, n.2, p. 15-28, 2000. 
JUBRAN, C. C. A. S. Parentetização. In: JUBRAN, C. C. A. S.; KOCH, I. G. V. (org.). Gramática do português culto falado no Brasil: construção do texto falado. Campinas: Ed. da Unicamp, 2006. p. 301-357. v.1.

MARINHO, J. H. C. Uma abordagem modular e interacionista da organização do discurso. Revista da Anpoll, São Paulo, n.16, p. 75-100, 2004.

ROULET, E. The description of text relation markers in the Geneva model of discourse organization. In: FISCHER, K. (org.). Approaches to Discourse Particles. Amsterdam: Elsevier, 2006. p. 115-131.

ROULET, E. Les relations de discours rhétoriques et praxéologiques dans la description des propriétés des constituants parenthétiques. Travaux de linguistique, Paris, n.49, p. 9-17, 2004.

ROULET, E. Une approche modulaire de la problematique des relations de discours. In: MARI, H. et al. (org.). Análise do discurso em perspectivas. Belo Horizonte: FALE/UFMG, 2003. p. 149-178.

ROULET, E. De la nécessité de distinguer des relations de discours sémantiques, textuelles et praxéologiques. In: ANDERSEN, H. L.; NØLKE, H. (org.). Macrosyntaxe et macro-sémantique: actes du colloque international d'Aarhus. Bern: Peter Lang, 2002. p.141-165.

ROULET, E. La description de l'organisation du discours: du dialogue au texte. Paris: Didier, 1999.

ROULET, E. Une description modulaire de l'organisation topicale d'un fragment d'entretien. Cahiers de linguistique française, Genebra, n.18, p. 11-32, 1996.

ROULET, E. On the structure of conversation as negotiation. In: PARRET, H.; VERSCHUEREN, J. (org.). (On) Searle on conversation. Amsterdam: Philadelphia: John Benjamins, 1992. p. 91-99.

ROULET, E. Variations sur la structure de l'échange langagier dans différentes situations d'interaction. Cahiers de linguistique française, Genebra, n.9, p. 27-37, 1988.

ROULET, E. Strategies d'interaction, modes d'implicitation et marqueurs illocutoires. Cahiers de linguistique française, Genebra, n.1, p. 80-103, 1980.

ROULET, E. et al. L'articulation du discours en français contemporain. Berne: Peter Lang, 1985.

ROULET, E.; FILLIETTAZ, L.; GROBET, A. Un modèle et un instrument d'analyse de l'organisation du discours. Berne: Peter Lang, 2001.

SAKAMOTO, L. Quem pariu o clima de loucura na política não pode reclamar de Luciano Huck. Blog do Sakamoto, 2018. Disponível em: https://blogdosakamoto. 
blogosfera.uol.com.br/2018/02/09/quem-pariu-o-clima-de-loucura-na-politica-naopode-reclamar-de-luciano-huck/. Acesso em: 21 maio 2021.

SCHEGLOFF, E. A. Sequence organization in interaction: a primer in Conversation Analysis I. Cambridge: Cambridge Press, 2007.

SEARLE, J. R. Expressão e significado: estudos da teoria dos atos da fala. São Paulo: Martins Fontes, 1995.

THOMPSON, S.; COUPER-KUHLEN, E. The clause as a locus of grammar and interaction. Discourse Studies, Thousand Oaks, v.7, n.4-5, p. 481-505, 2005.

Recebido em 15 de setembro de 2019

Aprovado em 08 de setembro de 2020 